\section{Estudo \\ (Debate}

em Cestão

Plamejamento
Revista Estudo \& Debate, Lajeado, v. 25, n. 2, 2018. ISSN 1983-036X

DOI: http://dx.doi.org/10.22410/issn.1983-036X.v25i2a2018.1620

\title{
ANÁLISE ESPACIAL DA POBREZA NOS MUNICÍPIOS GAÚCHOS ${ }^{1}$
}

\author{
Hellen Nunes de Farias ${ }^{2}$, Pedro Henrique Leivas ${ }^{3}$, Gabrielito Menezes ${ }^{4}$
}

\begin{abstract}
Resumo: O objetivo deste trabalho é analisar a dependência espacial da pobreza para os municípios do Rio Grande do Sul para o ano de 2010, através da análise exploratória de dados espaciais e da estimação de modelos econométricos especiais. Primeiramente, a dependência espacial é obtida através de uma medida de autocorrelação espacial global. Posteriormente, a estimação e comparação entre o Modelo por Mínimos Quadrados Ordinários, Modelo com Defasagem Espacial e o Modelo de Erro Espacial, indica que o melhor ajuste dos dados e, consequentemente, o resultado mais robusto é obtido pelo Modelo de Erro Espacial. Os resultados indicam a existência de dependência espacial para a pobreza. Os resultados ainda mostram que o impacto da renda per capita, da taxa de analfabetismo, entre outras variáveis, são significativos na determinação da pobreza na região.
\end{abstract}

Palavras-chave: Pobreza. Dependência Espacial. Rio Grande do Sul.

\begin{abstract}
The objective of this study is to analyze the spatial dependence of poverty for the municipalities of Rio Grande do Sul for the year 2010 through the exploratory spatial data analysis and estimation of special econometric models. First, the spatial dependence is obtained through a measure of global spatial autocorrelation. Subsequently, the estimation and comparison of the model by Ordinary least squares model with Spatial Lag Model and Space Error Model indicates that the best fit of the data and, consequently, the more robust is obtained by Space Error Model. The results indicate the existence of spatial dependence for poverty. The results also show that the impact of per capita income, illiteracy rate, among other variables, are significant in determining the poverty in the region.
\end{abstract}

Keywords: Poverty. Spatial Dependence. Rio Grande do Sul.

1 Texto inicial apresentado e publicado em: FARIAS, Hellen Nunes de; LEIVAS, Pedro Henrique; MENEZES, Gabrielito. Análise Espacial da Pobreza nos Municípios Gaúchos. In: LATIN AMERICAN AND CARIBBEAN REGIONAL SCIENCE ASSOCIATION CONGRESS E XV ENCONTRO NACIONAL DA ASSOCIAÇÃO BRASILEIRA DE ESTUDOS REGIONAIS E URBANOS, 1., 2017, São Paulo-SP. Anais... São Paulo-SP, ENABER, 2017.

2 Doutoranda em Economia Aplicada pelo Programa de Pós-Graduação em Economia da Universidade Federal do Rio Grande do Sul - PPGE/UFRG. E-mail: hellennunesfarias@gmail.com

3 Doutorando em Economia pelo Programa de Pós-Graduação em Economia da Pontifícia Universidade Católica do Rio Grande do Sul - PPGE/PUCRS. E-mail: leivas.pedro@gmail.com

4 Professor do Mestrado em Economia Aplicada do Programa de Pós-Graduação em Economia da Universidade Federal do Rio Grande - PPGE/FURG. E-mail: gabrielitorm@gmail.com

-- Artigo recebido em 04/11/2017. ACEIto em 22/05/2018. -- 


\section{INTRODUÇÁO}

A pobreza é um problema que acompanha a humanidade há séculos, conforme salientam Castel (1998) e Ávila (2013), e hoje é uma das grandes questóes que envolve políticas públicas. Por estar diretamente ligada a serviços de primeira necessidade, para muitos estudiosos a pobreza significa a privação de bens e serviços. Sen (2000 e 2001) afirma que a pobreza é uma das formas de perda da liberdade humana, ao passo que para Rocha (1998) a pobreza é um fenômeno para a qual não há um conceito próprio, há um equívoco que está associado a carência relativa a diferentes meios de condições de vida dos indivíduos.

Os estudos sobre pobreza, segundo a literatura, estão divididos em duas áreas: multidimensional e unidimensional (absoluta e relativa). A primeira aborda um estudo de pobreza mais heterogêneo com mais características, abrangendo não somente a renda, mas também a estrutura material de sobrevivência domiciliar da sociedade, tendo como objetivo criar indicadores multidimensionais que explicam essa deficiência. Já a segunda é sinônimo déficit de renda, na qual as famílias não conseguem manter um padrão de vida mínimo, não atendendo suas necessidades básicas de bens e serviços, as quais determinam seu bem-estar. A pobreza unidimensional é ao mesmo tempo uma pobreza absoluta. Pobreza relativa, por sua vez, é definida levando-se em conta o estilo de vida do restante da sociedade.

Em vista disso, no Brasil políticas de transferência de renda têm colaborado para a diminuição da extrema pobreza e da pobreza. Entretanto, persiste uma discrepância entre os mais ricos e os mais pobres. Estudos recentes (MILÁ, 2015; SOUZA; MEDEIROS, 2015) asseguram que ainda existe uma expressiva desigualdade de renda, bem como uma má distribuição dos pobres entre as regióes brasileiras. A esse respeito Anselin (1998) afirma que os indivíduos considerados pobres tendem a se concentrar em determinadas regióes específicas, acarretando assim, disparidades nesses lugares. Nesse sentido é relevante estudar os fenômenos da dependência espacial da pobreza no Rio Grande do Sul, em razão de ser um dos estados que mais contribui para economia do país.

A produçáo econômica do estado colabora com cerca de $7 \%$ do Produto Interno Bruto nacional, colocando o estado em $4^{\circ}$ lugar, atrás somente de São Paulo, Rio de Janeiro e Minas Gerais, conforme as informaçóes disponíveis no Atlas Socioeconômico do Rio Grande do Sul (Rio Grande do Sul, 2016). A proporção de pessoas pobres ${ }^{5}$ no estado, ou seja, com renda domiciliar per capita inferior a $\mathrm{R} \$ 140,00$ (linha de pobreza que o governo brasileiro utiliza para o Programas de transferência de renda - a preços de 2010), passou de $26,84 \%$, em 1991 , para $15,56 \%$, em 2000 , e para $6,37 \%$, em 2010 . Ainda que a proporção de pobres no Estado tenha caído consideravelmente desde 1991, é importante analisar os fatores que contribuem para que uma parcela da população ainda continue em situação de pobreza.

Em vista de uma perspectiva mais ampla, o objetivo desse estudo é fazer uma caracterização espacial da pobreza no estado do Rio Grande do Sul no período de 2010,

5 Porcentagem do extremamente pobres no RS: Em 1991: 9,89\%, 2000: 5,01\% e em 2010: 1,98\%. (Atlas do Desenvolvimento Humano do Brasil) 
utilizando ferramentas de análise espacial, para melhor entender e dimensionar espacialmente a pobreza no estado. Assim, na busca de identificação de clusters de pobreza será utilizado como base de dados o Censo Demográfico de 2010, realizado pelo Instituto Brasileiro de Geografia e Estatística -IBGE, para os 467 municípios gaúchos.

No modelo empírico, a taxa de pobreza será a variável dependente, ao passo que as variáveis explicativas compreendem uma ampla gama de características dos municípios, as quais podem exercer influência sobre a pobreza, tais como educação, renda e emprego. A estratégia empírica adotada fundamenta-se em realizar a Análise Exploratória de Dados Espaciais, a partir do uso da matriz de continuidade espacial e de medidas de autocorrelaçáo espacial global. Em seguida, estimar o modelo econométrico espacial e analisar os resultados. Este estudo baseia-se na análise realizada por Silva, Souza e Silva (2013) na qual atestaram a existência de dependência espacial da extrema pobreza para região Nordeste do Brasil.

Além, desta introdução o artigo encontra-se dividido em seis seções: a seção dois faz uma revisão da literatura sobre a relação entre pobreza e distribuição espacial; a terceira seção traz a descrição da metodologia utilizada e a estimação do modelo econométrico; a quarta seção traz a análise dos resultados, e a quinta seção apresenta as consideraçóes finais.

\section{REVISÁO DE LITERATURA}

Em busca de identificação de clusters de pobreza no Rio Grande do Sul, esta análise baseou-se em vários trabalhos que deram suporte para a fundamentação deste estudo. Entre os trabalhos destaca-se o de Romero (2006), no qual elabora uma análise espacial da pobreza municipal do estado de Minas Gerais, na qual utilizou como base o índice de desenvolvimento Humano (IDHM) e suas dimensóes (Renda, Longevidade e Educação). Os resultados encontrados por Romero (2006) apresentam evidências significativas de dependência espacial sugerindo que a localização geográfica é importante como determinante da pobreza em Minas Gerais.

Chiarini e Yano (2010) realizaram o mesmo estudo que Romero fez para Minas Gerais para o Rio Grande do Sul com o intuito de verificar a dinâmica da pobreza no estado no período de 1991 a 2000, período este que está relacionado com as reformas estruturais da economia brasileira (transição para o plano Real). Concluíram por meio do uso do indicador local de associação espacial (local indicator of spatial association - LISA ${ }^{6}$ ) e da estatística I-Moran Global que a pobreza se move no espaço, e que no período de 1991-200 houve no estado um processo de difusão de contágios, além de os clusters de pobreza terem aumentado. Já Ávila e Bagolin (2014) analisaram a distribuição espacial da pobreza no Rio Grande do Sul a partir de índices municipais de pobreza. Os índices foram utilizados para a criação de rankings municipais da pobreza que, comparados ao ranking do IDHM, mostraram-se consistentes para a medir a pobreza no estado. $\mathrm{O}$ trabalho verificou um padrão de associação espacial da pobreza no RS e da existência de clusters de pobreza.

6 Desenvolvido por Luc Anselin, é possível avaliar a hipótese de aleatoriedade espacial comparando os valores do indicador de cada regiáo com os indicadores das regióes vizinhas. 
Silva, Souza e Silva (2013) analisaram a dependência espacial da extrema pobreza para os municípios do Nordeste no ano de 2010, através da análise exploratória de dados espaciais e da estimação de um modelo econométrico especial através dos dados do Censo 2010. Os resultados atestaram a existência de dependência espacial da extrema pobreza, formando clusters em vários pontos da regiāo Nordeste. Constataram que a pobreza está mais concentrada nas áreas rurais das regióes analisadas, onde ao mesmo tempo se detecta problemas climáticos, baixa produtividade e menor cobertura dos serviços públicos de infraestrutura. Em relação a "Taxa de Dependência”, mostraram que há um número maior de pessoas muito jovens e idosas em condiçôes de pobreza, relativamente às pessoas em idade ativa.

Em relação a renda per capita, Andrade et al. (2004) afirmam que a formação de clusters espaciais de convergência com as regióes Norte e Nordeste em um grupo de renda baixa, e as regiōes Centro-Oeste, Sudeste e Sul em um grupo de renda elevada. Já para desigualdade de renda, Souza e Osório (2012) realizaram um estudo para o estado da Bahia no qual verificaram fluxos de renda concentrados em algumas regióes, enquanto outras sofrem com fome e escassez de serviços básicos. Isto tem causado gargalos sociais e econômicos disseminados por todo estado baiano, segundo os autores.

Outra variável importante para estimar a pobreza é a educação. Segundo Langoni (2005), existe uma ligação entre distribuição de renda no Brasil e o sistema educacional brasileiro. Por meio disso, Cavalcanti, Costa e Silva (2013) afirmam que devido aos programas de transferência de renda, a evasão escolar diminuiu no Nordeste, sendo que os resultados apontam para um efeito positivo sobre a frequência escolar para as famílias beneficiadas.

Além dos trabalhos mencionados, existem diversos estudos que enfatizaram a questão espacial da pobreza no Brasil e em outros países. E também evidenciam a importância da economia regional como meio de tentar resolver o problema de distribuiçấo de renda e desigualdades sociais que são táo relevantes para o desenvolvimento de um país/região/ município.

\section{METODOLOGIA}

\subsection{Dados}

Os dados utilizados no presente trabalho são provenientes do Censo Demográfico 2010, abrangendo informaçóes estatísticas para 467 municípios do Estado. Os indicadores calculados para cada um dos municípios gaúchos foram:

- Grau de formalizaçáo dos ocupados 18 anos ou mais: Razão entre o número de pessoas de 18 anos ou mais formalmente ocupada e o número total de pessoas ocupadas nessa faixa etária.

- Índice de Gini: Mede o grau de concentração da distribuição de renda domiciliar per capita de uma determinada população e em um determinado espaço geográfico. Interpretaçáo: Quando o índice tem valor igual a um (1), existe perfeita desigualdade, isto é, a renda domiciliar per capita é totalmente apropriada por um 
único indivíduo. Quando ele tem valor igual à zero (0), tem-se perfeita igualdade, isto é, a renda é distribuída na mesma proporção para todos os domicílios. Quanto mais próximo da unidade, maior a desigualdade na distribuiçáo de renda.

- Populaçáo total em domicílios particulares permanentes: População residente em domicílios particulares permanentes. Exclui os residentes em domicílios coletivos, como pensóes, hotéis, prisóes, quartéis, hospitais.

- Proporção da população em domicílios com banheiro e água em canada: Razão entre a população que vive em domicílios particulares permanentes com água encanada em pelo menos um de seus cômodos e com banheiro exclusivo e a população total residente em domicílios particulares permanentes;

- Proporçáo da populaçáo em domicílios com coleta de lixo: Razão entre a população que vive em domicílios com coleta de lixo e a população total residente em domicílios particulares permanentes;

- Proporçáo da populaçáo extremamente pobre: Consiste no percentual da população residente em domicílios particulares permanentes com renda mensal domiciliar per capita de até 70 reais dividida pela população total, caracterizando a população extremamente pobre ou em situação de miséria;

- Proporçáo da população pobre: É variável dependente do modelo, e consiste no percentual da população residente em domicílios particulares permanentes com renda mensal domiciliar per capita de até 140 reais dividida pela população total, caracterizando a população pobre;

- Razáo de dependência: Razão de dependência é medida pela razão entre o número de pessoas com 14 anos ou menos e de 65 anos ou mais de idade (população dependente) e o número de pessoas com idade de 15 a 64 anos (população potencialmente ativa);

- Renda per capita: Consiste no valor (em $\mathrm{R} \$$ ) do rendimento nominal médio mensal domiciliar per capita das pessoas residentes em domicílios particulares com rendimento;

- Taxa de analfabetismo: É calculada a partir da divisão da população com 15 anos ou mais de idade analfabeta pela população total nesta mesma faixa de idade;

A variável dependente nesse estudo é a pobreza enquanto que as demais são variáveis explicativas. Ressalta-se que devido à heterogeneidade entre os municípios gaúchos, e almejando minimizar problemas associados com a grande variância e não-normalidade dos dados.

A Tabela 1 mostra a descrição das variáveis quanto aos seus valores médios, de dispersão e extremos. Chama à atenção a alta amplitude em todas as variáveis e o fato de todas as variáveis apresentam valores máximos bem acima da média. 
Tabela 1 - Estatísticas descritivas das variáveis do modelo

\begin{tabular}{l|c|c|c|c}
\hline Variáveis & Média & Desvio Padráo & Mínimo & Máximo \\
\hline $\begin{array}{l}\text { Grau de formalização dos ocupados - 18 } \\
\text { anos ou mais }\end{array}$ & 52,28 & 16,57 & 12,29 & 87,23 \\
\hline Índice de Gini & 0,47 & 0,07 & 0,28 & 0,68 \\
\hline $\begin{array}{l}\text { Populaçáo total em domicílios particulares } \\
\text { permanentes }\end{array}$ & 22.596 & 77.251 & 1.216 & 1.394 .270 \\
\hline $\begin{array}{l}\text { Proporção da população em domicílios com } \\
\text { banheiro e água encanada }\end{array}$ & 95,27 & 5,60 & 55,27 & 100,00 \\
\hline $\begin{array}{l}\text { Proporçáo da população em domicílios com } \\
\text { coleta de lixo }\end{array}$ & 98,24 & 2,69 & 81,00 & 100,00 \\
\hline Proporção de extremamente pobres & 3,30 & 3,64 & 0,00 & 29,51 \\
\hline Proporção de pobres & 8,77 & 6,65 & 0,00 & 43,55 \\
\hline Razáo de dependência & 45,27 & 4,70 & 33,53 & 69,83 \\
\hline Renda domiciliar per capita & 745,30 & 208,80 & 336,40 & $1.758,00$ \\
\hline Taxa de analfabetismo - 15 anos ou mais & 6,71 & 3,34 & 0,95 & 20,11 \\
\hline
\end{tabular}

Fonte: elaborado pelos autores, com base nos microdados do Censo Demográfico 2010.

\subsection{Análise exploratória de dados espaciais}

A análise exploratória de dados espaciais (AEDE), conhecida em inglês como Exploratory Spatial Data Analysis (ESDA), está fundamentada nos aspectos espaciais contidos na base dos dados. Para tanto, considera a autocorrelação e a heterogeneidade espacial. $\mathrm{O}$ objetivo desta metodologia é apresentar a distribuição espacial, os clusters espaciais, verificar a presença de diferentes regimes espaciais ou outras formas de instabilidade espacial e identificar outliers (ALMEIDA et al., 2005).

A autocorrelação espacial, conforme Haining apud Almeida (2004) está relacionada fundamentalmente a quatro processos. $\mathrm{O}$ primeiro refere-se a um processo de difusão que consiste na implementação de um fator de interesse por parte da população fixa. O segundo está associado à troca de mercadorias e a transferência de renda. O terceiro processo envolve a interação entre as diversas regióes, ou seja, eventos de uma região podem influenciar eventos em outras regióes. O quarto processo está relacionado à dispersão ou do espraiamento de um atributo.

A heterogeneidade espacial ocorre quando há instabilidade estrutural no espaço, ou seja, manifesta-se quando advém da instabilidade estrutural no espaço, fazendo com que haja distintas respostas, dependendo da região ou da escala espacial (ALMEIDA, 2004).

Nesta perspectiva, Anselin (1988), enfatiza que a noção de dependência espacial implica na necessidade de determinar a influência de uma unidade particular nas outras unidades do sistema espacial. Convencionalmente, isto é expresso na noção de vizinhança mediante a construção de matrizes de pesos espaciais. 


\section{Matriz de pesos espaciais (W)}

De acordo com Almeida (2004), o conceito de matriz de pesos espaciais (W) tem como fundamento a contiguidade, que pode ser determinada conforme a vizinhança; a distância geográfica ou socioeconômica; ou a combinaçáo das duas. Anselin (1988) destaca a importância da escolha entre as matrizes, pois os resultados podem variar dependendo da escolha da matriz.

Figueiredo apud Pinheiro (2007) descreve que a percepção dos efeitos espaciais de uma unidade sobre as diversas é dada por meio de ponderaçôes, ou seja, a variável observada em cada região recebe uma ponderação quando a mesma for vizinha da região analisada.

A matriz de pesos espaciais indica qual o modelo de fronteira é considerado no teste. Os dois principais tipos de matriz de pesos são: Rainha e Torre, como mostrada na figura abaixo.

Figura 2 - Matrizes de pesos espaciais

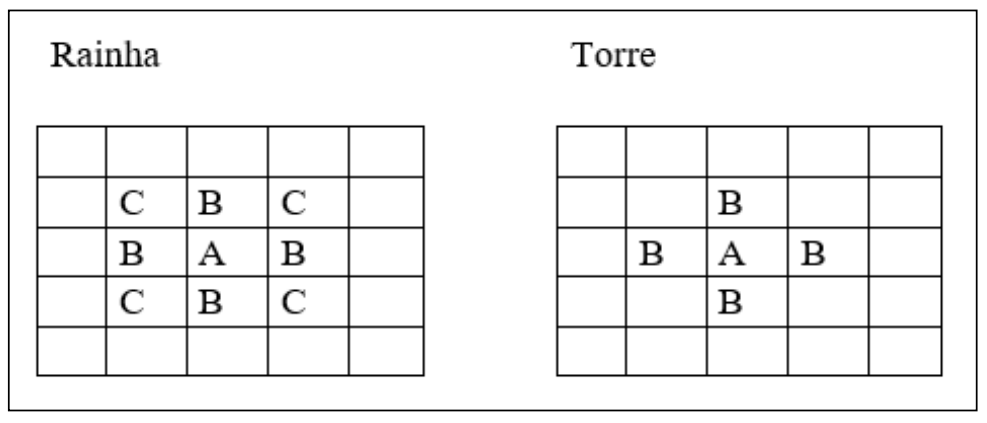

Fonte: Baseado em Anselin (1988, p. 22)

$\mathrm{Na}$ Rainha são consideradas vizinhas todas as unidades que dividem qualquer tipo de fronteira com a unidade analisada: uma borda comum ou um nó comum. Enquanto que, na Torre, são consideradas vizinhas apenas as unidades que compartilham uma borda comum.

Neste trabalho, conforme apresentado Monasterio e Ávila (2004), Ávila (2007), Oliveira e Marques Junior (2008) e Oliveira (2008), optou-se por empregar o padrão denominado Rainha, com grau de vizinhança igual a um. De tal modo serão consideradas vizinhas todas as unidades que compartilham qualquer tipo de fronteira com a unidade analisada.

\section{Autocorrelação espacial global}

O estudo da AEDE tem como passo inicial examinar a aleatoriedade dos dados espaciais, significando que os valores do atributo numa região não dependem dos valores desse atributo nas regiōes vizinhas, ou em outras palavras, se existe alguma relação espacial entre as unidades em estudo.

$\mathrm{Na}$ literatura há um conjunto de estatísticas que investigam a presença da autocorrelaçáo espacial, ou seja, se existe a coincidência da semelhança de valores de uma variável com a semelhança da localização dessa variável (ALMEIDA, 2004). 
Segundo Oliveira (2008), a maneira mais utilizada para testar a autocorrelação espacial é o I de Moran. Enfatizando o exposto, Ávila (2007) afirma que o mesmo se restringe a responder se a distribuição é não-aleatória, não sendo possível identificar quais unidades são espacialmente correlacionadas. Formalmente, essa estatística é dada por:

$$
I=\frac{\sum_{i=1}^{n} \sum_{j=1}^{n} w_{j} x_{i} x_{j}}{\sum_{i=1}^{n} x_{i}^{2}}
$$

Onde:

$n=$ número de observações;

$w_{i j}=$ representa os elementos da matriz de pesos espaciais;

$x_{i}$ e $x_{j}=$ são os valores da variável analisada em desvios da média.

No momento que a estatística I de Moran é próxima de +1 denota que existe uma autocorrelação positiva, ou seja, valores altos (baixos) tendem a estar localizados ao arredor de valores altos (baixos). Se for próximo de -1 , o contrário ocorre: valores altos estarão ao redor de valores baixos, e vice-versa. Quando o mesmo é zero, não existe autocorrelação espacial.

A significância da estatística I de Moran é baseada em uma abordagem de permutação. Analisando se a probabilidade do I de Moran calculado ter sido encontrado casualmente, ou seja, gera-se uma distribuiçáo aleatória de índices de Moran e confronta-se com o valor encontrado. Desse modo, é possível conhecer a probabilidade do I de Moran ser estatisticamente significativo ou não (ANSELIN, 2003; ÁVILA, 2007).

\section{Diagramas de dispersão de Moran}

O diagrama de dispersão de Moran (Moran's scatterplot) é uma das formas de interpretar a estatística I de Moran (ALMEIDA et al., 2006). Nesta perspectiva, Almeida (2004) diz que é possível visualizar graficamente a associação espacial, que mostra a defasagem espacial da variável de interesse no eixo $\mathrm{Y}$ e o valor dessa variável no eixo X. 
Figura 3 - Diagrama de dispersão de Moran (Moran's scatterplot)

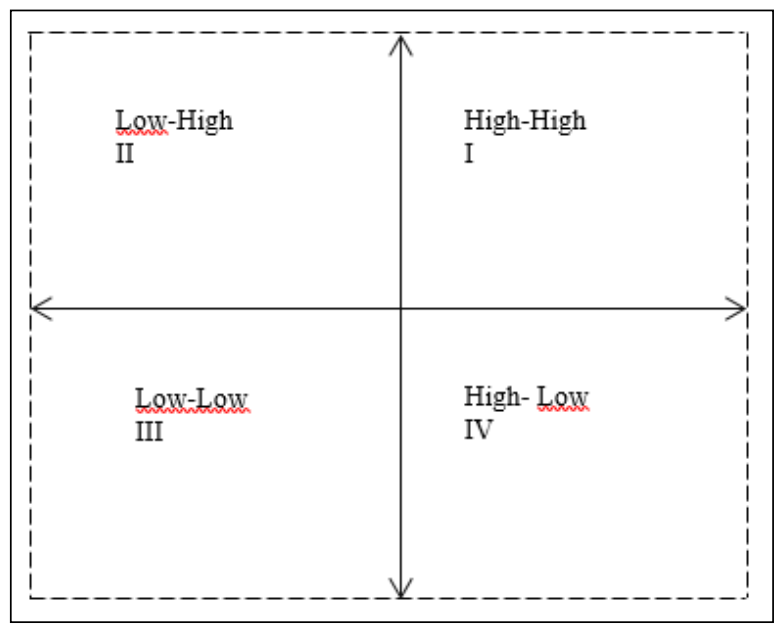

Fonte: Baseado em Aldstadt (2010).

Os pontos que se encontram no primeiro quadrante mostram as unidades que apresentam altos valores para a variável em análise cercada por unidades que também apresentam valores acima da média para a variável em análise. Esse quadrante é classificado como High-High (HH).

No segundo quadrante são indicadas as unidades com valores baixos de dadas variáveis cercadas por vizinhos que apresentam valores altos. Esse quadrante é geralmente classificado como Low-High (LH).

Já os pontos no terceiro quadrante, mostram as unidades que apresentam valores abaixo da média para as variáveis em análise cercados por unidades que igualmente apresentam baixos valores. Esse quadrante é classificado como Low-Low (LL).

Por fim, o quarto quadrante é constituído pelas unidades que apresentam altos valores para as variáveis em análise cercados por unidades de baixos valores. Esse quadrante é classificado como High-Low (HL).

As unidades que estão localizadas nos quadrantes $\mathrm{HH}$ e LL apresentam autocorrelação espacial positiva, ou seja, estas unidades apresentam altos (baixos) valores de uma variável contornados por altos (baixos) valores. No entanto, os quadrantes LH e HL apresentam autocorrelaçâo espacial negativa, ou seja, estas unidades apresentam altos (baixos) valores cercados por baixos (altos) valores (PINHEIRO, 2007).

Os Gráficos 1 e 2 a seguir apresentam o diagrama de dispersão de Moran para a proporção de extremamente pobres e para a proporção de pobres, respectivamente. Em relação ao primeiro gráfico, pode-se constatar que a maior parte dos municípios estão localizados no quadrante I e III. Esses resultados estáo de acordo com I de Moran, uma vez que mostraram que a maioria dos municípios gaúchos se encontram nos quadrantes que apresentam a existência de autocorrelação espacial positiva, ou seja, valores dos 
extremamente pobres de um determinado município semelhante aos municípios ao lado formando assim, clusters nessas regióes.

Gráfico 1 - Diagrama de dispersão de Moran da proporção extremamente pobres

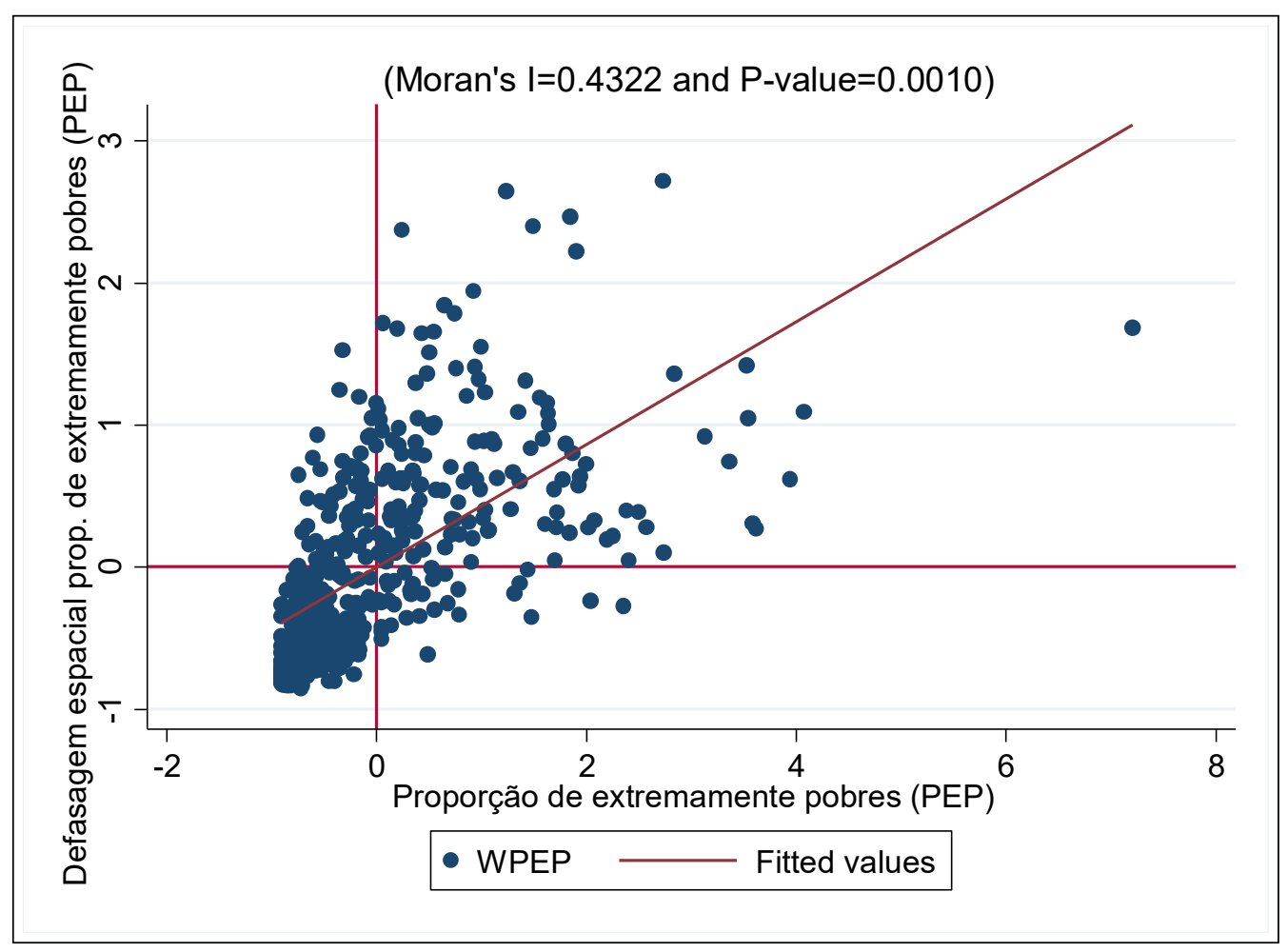

Fonte: elaborado pelos autores, com base nos microdados do Censo Demográfico 2010.

No Gráfico 2, os quadrantes I e III denota os pontos com a associaçáo espacial positiva, ou seja, o local e a média da vizinhança apresenta, os valores semelhantes. As regiōes com essas características formam clusters com valores similares. 
Gráfico 02 - Diagrama de dispersão de Moran para a proporção de pobres

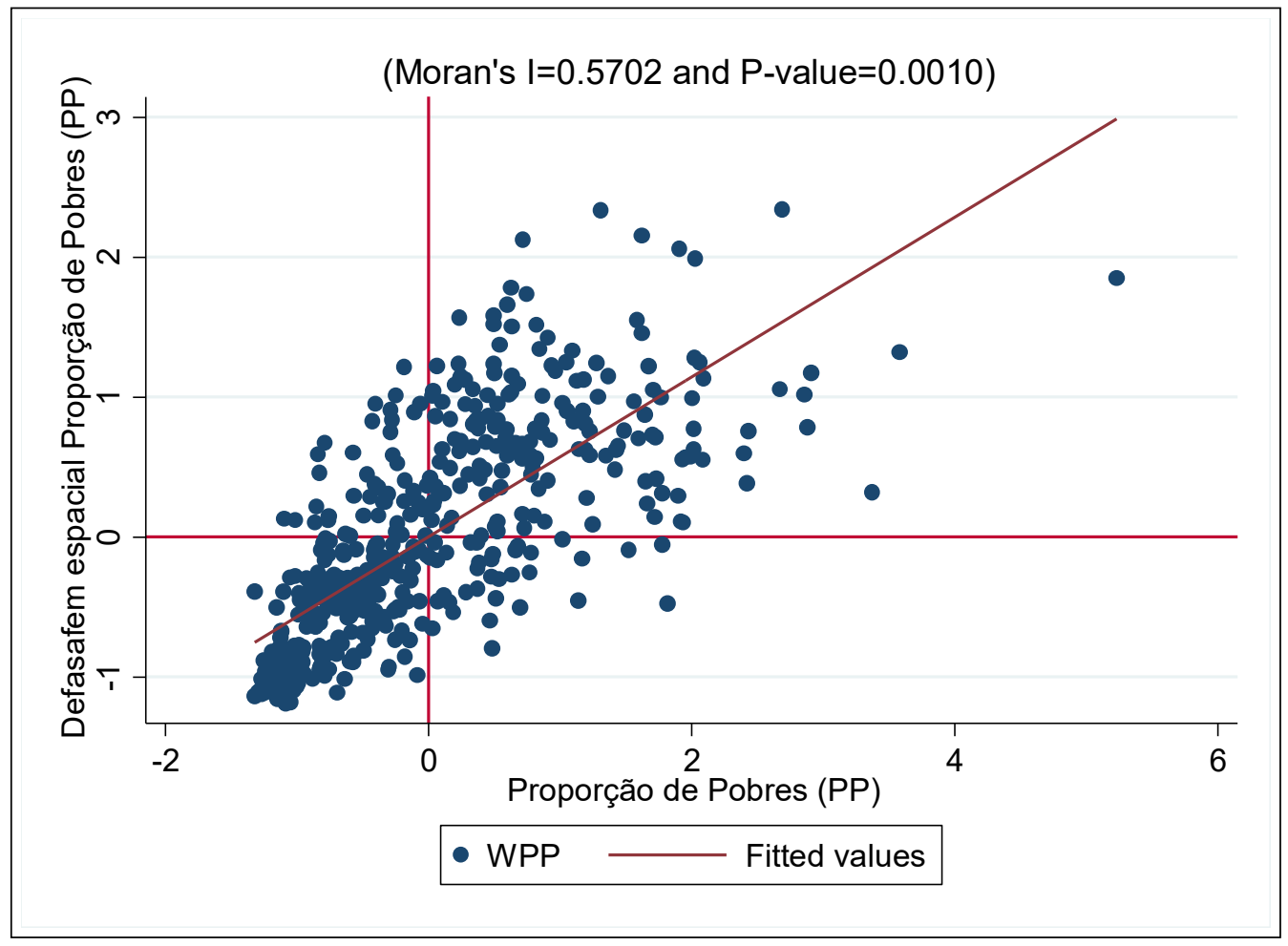

Fonte: elaborado pelos autores, com base nos microdados do Censo Demográfico 2010.

Portanto, para ambos os gráficos a dispersão estão nos quadrantes I e III, ou seja, nos quadrantes em que um município com alto índice de pobreza está cercado por municípios com altas taxas de pobreza, o mesmo ocorrendo com municípios com baixa pobreza, cercado por municípios com o mesmo atributo.

Já a Tabela 2 apresenta o I de Moran das variáveis que serão utilizadas no trabalho. É possível observar que todas as variáveis exibem autocorrelaçáo espacial, segundo a estatística de Moran, sendo a maior dependência observada na proporção de pobres.

Tabela 2 - I de Moran das variáveis do modelo

\begin{tabular}{l|c|r|r}
\hline \multicolumn{1}{c|}{ Variáveis } & I & \multicolumn{1}{c|}{ z } & \multicolumn{1}{c}{ p-value } \\
\hline Grau de formalização dos ocupados - 18 anos ou mais & 0.389 & 14.270 & 0.000 \\
\hline Índice de Gini & 0.392 & 14.396 & 0.000 \\
\hline População total em domicílios particulares permanentes & 0.215 & 10.849 & 0.000 \\
\hline $\begin{array}{l}\text { Proporção da população em domicílios com banheiro e água } \\
\text { encanada }\end{array}$ & 0.220 & 8.259 & 0.000 \\
\hline Proporção da população em domicílios com coleta de lixo & 0.157 & 5.886 & 0.000 \\
\hline
\end{tabular}




\begin{tabular}{l|r|r|r}
\hline \multicolumn{1}{c|}{ Variáveis } & I & z & \multicolumn{1}{c}{ p-value } \\
\hline Proporção de extremamente pobres & 0.432 & 16.001 & 0.000 \\
\hline Proporção de pobres & 0.570 & 20.947 & 0.000 \\
\hline Razão de dependência & 0.462 & 16.996 & 0.000 \\
\hline Renda domiciliar per capita & 0.446 & 16.421 & 0.000 \\
\hline Taxa de analfabetismo - 15 anos ou mais & 0.585 & 21.481 & 0.000 \\
\hline
\end{tabular}

Fonte: elaborado pelos autores, com base nos microdados do Censo Demográfico 2010.

\subsection{Modelo empírico}

Conforme expóem Anselin (1988) os efeitos espaciais devem ser considerados em sua forma funcional durante a especificação do modelo, identificando de maneira apropriada questôes intrínsecas aos efeitos de transbordamento entre regióes. Nesta perspectiva, considerar-se a presença de autocorrelação espacial no modelo econométrico, através do teste I de Moran nos resíduos gerados por meio da regressão, utilizando o método de MQO. Caso a presença de autocorrelação espacial seja confirmada, a análise por MQO não levaria em consideração problemas de autocorrelação e heterogeneidade espaciais, fornecendo estimativas inconsistentes e/ou ineficientes. Sendo neste caso, indispensável o emprego de um modelo econométrico espacial.

\section{Modelos por Minimos Quadrados Ordinários (MQO)}

O primeiro modelo a ser considerado, é o modelo de mínimos quadrados ordinários (MQO), o qual é não-espacial e segue a estrutura do modelo clássico de regressão linear. O mesmo pode ser representado como:

$$
Y=X \beta+\varepsilon
$$

Onde $X$ é uma matriz de $n$ por $k$ com variáveis explicativas.

\section{Modelo Espacial Autoregressivo (Spatial Autoregressive Model - SAR)}

O modelo de espacial autoregressivo assume que a autocorrelação espacial pode ser captada por meio da estimativa de um coeficiente relacionado com a variável dependente defasada espacialmente. A equação abaixo ilustra o modelo:

$$
Y=\rho W Y+X \beta+\varepsilon
$$

em que $Y$ é um vetor $n$ por 1 de observaçóes sobre a variável dependente, $W Y$ é um vetor $n$ por 1 de defasagens espaciais para a variável dependente, $p$ é o coeficiente autoregressivo espacial (um escalar), $X$ é uma matriz $n$ por $k$ de observaçóes sobre as variáveis explicativas exógenas com um vetor associado $k$ por 1 de coeficientes de regressão $\beta$ e $\varepsilon$ é um vetor $n$ por 1 de termos de erro aleatório distribuído aleatoriamente (ALMEIDA, 2012). 


\section{Modelo de Erro Espacial (Spatial Error Model - SEM)}

A dependência espacial subjacente pode ser residual quando a sua origem não é a unidade substantiva, caso em que a especificação correta seria dada pelo seguinte modelo de erro espacial:

$$
Y=X \beta+\lambda W \varepsilon+\mu
$$

A correlação espacial é capturada aqui por $\lambda$ através do termo de erro do modelo, $\varepsilon$. A dependência espacial residual poderia ser explicada pela omissão de variáveis cruciais que se encontram espacialmente correlacionado ou quaisquer erros de medida (MORENO; VAYÁ, 2000).

\section{RESULTADOS}

Nesta seção são apresentados os resultados das análises dos determinantes da extrema pobreza nos municípios do Rio Grande do Sul, estimados, com base nas variáveis disponíveis, conforme os três modelos descritos na metodologia sobre econometria espacial, a fim de verificar qual deles apresenta um melhor ajuste aos dados e, consequentemente, mostrem resultados mais robustos.

Tabela 3 - Modelo econométrico - proporção de extremamente pobres

(1) (2)

(3)

\begin{tabular}{lccc} 
Variáveis & MQO & SAR & SEM \\
\hline Grau de formalização dos ocupados - 18 anos ou mais & $-0.0297^{* * *}$ & $-0.0290^{* * *}$ & $-0.0331^{* * *}$ \\
& $(0.0082)$ & $(0.0068)$ & $(0.0070)$ \\
Índice de Gini & $18.0577^{* * *}$ & $16.3364^{* * *}$ & $20.8231^{* * *}$ \\
& $(2.0340)$ & $(1.9351)$ & $(2.0748)$ \\
População total em domić́lios particulares permanen- & 0.0000 & 0.0000 & $0.0000^{*}$ \\
tes & $(0.0000)$ & $(0.0000)$ & $(0.0000)$ \\
& & & \\
Proporção da população em domićlios com banheiro & $-0.1551^{* * *}$ & $-0.1573^{* * *}$ & $-0.1347^{* * *}$ \\
e água encanada & $(0.0540)$ & $(0.0216)$ & $(0.0218)$ \\
& & & \\
Proporção da população em domicílios com coleta de & -0.0483 & -0.0406 & -0.0298 \\
lixo & $(0.0545)$ & $(0.0382)$ & $(0.0376)$ \\
& 0.0162 & 0.0198 & 0.0313 \\
Razão de dependência & $(0.0451)$ & $(0.0311)$ & $(0.0323)$ \\
& $-0.0072^{* * *}$ & $-0.0066^{* * *}$ & $-0.0085^{* * *}$ \\
Renda domiciliar per capita & $(0.0010)$ & $(0.0008)$ & $(0.0009)$ \\
& 0.0774 & 0.0526 & 0.0153 \\
Taxa de analfabetismo - 15 anos ou mais & $(0.0592)$ & $(0.0486)$ & $(0.0530)$
\end{tabular}




\begin{tabular}{lccc} 
Variáveis & MQO & SAR & SEM \\
\hline Constant & $20.0185^{* * *}$ & $19.4144^{* * *}$ & $15.7626^{* * *}$ \\
& $(6.9110)$ & $(4.4715)$ & $(4.6219)$ \\
\hline Rho & $0.1212^{* *}$ & \\
Lambda & $(0.0485)$ & \\
& & & $0.3804^{* * *}$ \\
Sigma2 & & $4.1809^{* * *}$ & $3.8971^{* * *}$ \\
& & $(0.2737)$ & $(0.2580)$ \\
Observaçóes & 4667 & 467 \\
R-quadrado & & & \\
\hline Testes de diagnóstico para dependência espacial na regressão de MQO & & \\
I de Moran & $5.6820^{* * *}$ & & \\
Modelo de Erro Espacial: & & & \\
Multiplicador de Lagrange & & & \\
Multiplicador de Lagrange (Robusto) & & \\
Modelo de Defasagem Espacial: & $28.285^{* * *}$ & & \\
Multiplicador de Lagrange & $23.237^{* * *}$ & & \\
Multiplicador de Lagrange (Robusto) & & & \\
\hline
\end{tabular}

Erros-padrão robustos entre parênteses.

${ }^{* * *} \mathrm{p}<0.01,{ }^{* *} \mathrm{p}<0.05,{ }^{*} \mathrm{p}<0.1$

A Tabela 3 apresenta os resultados dos modelos estimados para a proporção de extremamente pobres. Os resultados confirmam os sinais esperados. Como todos os coeficientes foram estatisticamente significantes a $1 \%$, pode-se dizer que um aumento no Índice de Gini causa um aumento na proporção da população extremamente pobre. Enquanto isso, um aumento no grau de formalização dos ocupados, na proporção da população em domicílios com banheiro e água encanada, e na renda domiciliar per capita contribuem para diminuir os extremamente pobres. $\mathrm{O}$ teste R-quadrado indica que as variáveis explicativas explicam $67,81 \%$ da população dos municípios extremamente pobres no Rio Grande do Sul.

Como verifica-se pelo teste de $I$ de Moran $(\mathbf{0 , 4 3 2})$ existe dependência espacial entre os municípios do estado. Com os testes dos Multiplicadores de Lagrange, tanto o modelo de Defasagem Espacial como o modelo de Erro Espacial mostraram-se estatisticamente significantes a $1 \%$, é possível afirmar que o método de Mínimos Quadrados Ordinários não é o mais apropriado. Desse modo, é preciso verificar as versóes robustas dos dois testes (Multiplicador Lagrange Robusto) e escolher como modelo apropriado o que for mais significante. Uma vez que o teste do Multiplicador Lagrange robusto para (SEM) é 
significante a $1 \%$, enquanto que o teste robusto para (SAR) não é significante. Portanto, o modelo de Erro Espacial é o mais apropriado. Assim, o termo do erro auto regressivo espacial lambda positivo (0.3804) é estatisticamente significativo a $1 \%$, indica que os efeitos não modelados apresentam uma autocorrelação espacial positiva.

Portanto, os coeficientes das Proxies Renda domiciliar per capita e Taxa de analfabetismo permitem, respectivamente, inferir numa relação inversa e proporcional destas variáveis com a extrema pobreza, indicando que tanto o aumento da renda quanto o nível educacional médio afetam a condição de pobreza dos municípios gaúchos. Assim sendo, um aumento de um real na renda domiciliar per capita média reduz a proporção de extremamente pobres em 0,0085 pontos percentuais (p.p.). Os resultados para a taxa de analfabetismo não mostraram-se estatisticamente significativos para nenhum dos modelos estimados.

O coeficiente do Grau de formalização dos ocupados aponta que a proporção de extremamente pobres reduz-se em 0,0331 p.p. caso a proporção dos trabalhadores formais se eleve em um p.p.. Esse resultado denota que os indivíduos extremamente pobres no mercado de trabalho formal ajudam a elevar os rendimentos e condição de vida da população. Outro coeficiente relevante para os municípios extremamente pobres é proporção da população em domicílios com banheiro e água encanada, na qual impactam de forma que quanto menor a cobertura dos serviços maior tende a ser os indicadores de pobreza para os municípios gaúchos. Tal fato fica evidenciado na percepção de que a pobreza está mais concentrada nas áreas rurais das regióes analisadas, onde ao mesmo tempo se detecta uma menor cobertura de serviços de infraestrutura. Já a variável "Taxa de Dependência”, não foi significativa aos municípios extremamente pobres.

Tabela 4 - Modelo econométrico - proporção de pobres

\begin{tabular}{lccc}
\hline \multicolumn{1}{c}{ Variáveis } & $\mathbf{( 4 )}$ & $\mathbf{( 5 )}$ & $\mathbf{( 6 )}$ \\
& MQO & SAR & SEM \\
\hline Grau de formalização dos ocupados - 18 anos ou mais & $-0.0456^{* * *}$ & $-0.0447^{* * *}$ & $-0.0502^{* * *}$ \\
& $(0.0087)$ & $(0.0080)$ & $(0.0081)$ \\
Índice de Gini & $37.764^{* * *}$ & $35.503^{* * *}$ & $40.330^{* * *}$ \\
& $(2.2263)$ & $(2.3854)$ & $(2.3490)$ \\
População total em domicílios particulares permanentes & $0.0000^{* * *}$ & $0.0000^{* * *}$ & $0.0000^{* * *}$ \\
& $(0.0000)$ & $(0.0000)$ & $(0.0000)$ \\
Proporção da população em domicílios com banheiro e & $-0.2074^{* * *}$ & $-0.2133^{* * *}$ & $-0.1890^{* * *}$ \\
água encanada & $(0.0447)$ & $(0.0254)$ & $(0.0248)$ \\
& & & -0.0168 \\
Proporção da população em domicílios com coleta de & -0.0468 & -0.0399 & $-0.0430)$ \\
lixo & $(0.0572)$ & $(0.0446)$ & $\left(0.0694^{* * *}\right.$ \\
Razão de dependência & $0.0864^{* *}$ & $0.0884^{* *}$ & $0.1063)$ \\
& $(0.0438)$ & $(0.0363)$ & $(0.0371)$
\end{tabular}




\begin{tabular}{|c|c|c|c|}
\hline Variáveis & MQO & SAR & SEM \\
\hline Renda domiciliar per capita & $\begin{array}{c}-0.0164^{* * *} \\
(0.0010)\end{array}$ & $\begin{array}{c}-0.0155^{* * *} \\
(0.0010)\end{array}$ & $\begin{array}{c}-0.0173^{* * *} \\
(0.0010)\end{array}$ \\
\hline Taxa de analfabetismo - 15 anos ou mais & $\begin{array}{c}0.2436^{* * *} \\
(0.0691)\end{array}$ & $\begin{array}{c}0.2203^{* * *} \\
(0.0568)\end{array}$ & $\begin{array}{c}0.1935^{* * *} \\
(0.0604)\end{array}$ \\
\hline Constant & $\begin{array}{c}24.441^{* * *} \\
(6.8811) \\
\end{array}$ & $\begin{array}{c}24.167^{* * *} \\
(5.2153)\end{array}$ & $\begin{array}{c}18.789^{* * *} \\
(5.2796)\end{array}$ \\
\hline Rho & & $\begin{array}{c}0.0681^{* *} \\
(0.0335)\end{array}$ & \\
\hline Lambda & & & $\begin{array}{c}0.4306^{* * *} \\
(0.0613)\end{array}$ \\
\hline Sigma2 & & $\begin{array}{c}5.7006^{* * *} \\
(0.3731)\end{array}$ & $\begin{array}{c}5.0963^{* * *} \\
(0.3381)\end{array}$ \\
\hline Observações & 467 & 467 & 467 \\
\hline R-quadrado & 0.8694 & & \\
\hline
\end{tabular}

Testes de diagnóstico para dependência espacial na regressão de MQO

I de Moran 7.128***

Modelo de Erro Espacial:

Multiplicador de Lagrange

Multiplicador de Lagrange (Robusto)

Modelo de Defasagem Espacial:

Multiplicador de Lagrange $\quad 4.356$

Multiplicador de Lagrange (Robusto) $\quad 1.061$

Erros-padrão robustos entre parênteses.

${ }^{* * *} \mathrm{p}<0.01,{ }^{* *} \mathrm{p}<0.05,{ }^{*} \mathrm{p}<0.1$

Partindo para análise proporção de pobres, a Tabela 4 apresenta os resultados dos modelos estimados. Os resultados novamente confirmam os sinais esperados das variáveis. A maioria dos coeficientes foram estatisticamente significantes a $1 \%$, pode-se dizer que um aumento na variável Índice de Gini na variável razão de dependência e na taxa de analfabetismo causa um aumento na população dos municípios e pobres. Todavia, um aumento no grau de formalização dos ocupados, na proporção da população em domicílios com banheiro e água encanada, e na renda domiciliar per capita contribuem para diminuir a proporção pobres. $\mathrm{O}$ teste $\mathrm{R}$-quadrado indica que as variáveis explicativas explicam $86,9 \%$ da população dos municípios pobres no Rio Grande do Sul.

Como se verifica pelo teste de $I$ de Moran $(\mathbf{0 , 5 7 0})$ existe dependência espacial entre os municípios gaúchos. Com os testes dos Multiplicadores de Lagrange, tanto o modelo de Defasagem Espacial como o modelo de Erro Espacial mostraram-se estatisticamente 
significantes a 1\%, então é possível afirmar que o método de Mínimos Quadrados Ordinários não é o mais apropriado. Desse modo, o modelo de Erro Espacial é o mais apropriado por possuir o termo de erro auto regressivo espacial lambda positivo $(0,4306)$ estatisticamente significativo a $1 \%$, indica que os efeitos não modelados apresentam uma autocorrelação espacial positiva.

Portanto, os coeficientes das Proxies Renda domiciliar per capita e Taxa de analfabetismo permitem respectivamente inferir numa relação inversa e proporcional destas variáveis com pobreza, indicando que tanto o aumento da renda quanto o nível educacional médio a afetam a condição de pobreza dos municípios gaúchos. Assim sendo, um aumento de um real na renda domiciliar per capita média reduz a proporção de pobres em 0,173 p.p., no entanto uma redução de um p.p. na taxa de analfabetismo o modelo prevê uma queda em torno de 0,1935 p.p. da população em situação de pobreza.

O coeficiente Grau de formalização dos ocupados aponta que a proporção de pobres reduz em 0, 0502 p.p. caso a proporção dos trabalhadores formais se eleve em um p.p.. Esse resultado mostra que os indivíduos pobres no mercado de trabalho formal ajudam a elevar os rendimentos e condição de vida da populaçáo. Outro coeficiente relevante para os municípios pobres é Proporção da população em domicílios com banheiro e água encanada, na qual impactam de forma que quanto menor a cobertura dos serviços maior tende a ser os indicadores de pobreza para os municípios gaúchos.

Em relação à variável "Taxa de Dependência”, ou seja, número de pessoas muito jovens (com menos de 15 anos) e idosas (com mais de 64 anos), relativamente às pessoas em idade ativa (15 a 64 anos), observa-se uma maior tendência de possuir índices elevados de pobreza. Esse resultado condiz com o esperado, pois geralmente os responsáveis em manter o domicílio são aquelas pessoas em idade ativa que participam do mercado de trabalho e auferem de algum tipo de renda.

Com base nos resultados apresentados, o segundo modelo - proporção de pobresfoi mais relevante para mostrar a dependência espacial da pobreza para os municípios gaúchos, dado que seus resultados se apresentaram mais intensos. Mas cabe salientar que no Rio Grande do Sul existe a presença de dependência espacial para os munícipios extremamente pobres. Dessa forma, ambos os níveis de pobreza atrelam diversos problemas socioeconômicos no estado.

Em vista disso, recomenda-se aos formuladores de políticas, açóes públicas que possibilitem a formulação eficiente de capital humano; criação de emprego e renda com distribuição justa dos benefícios, uma maior cobertura dos serviços de água, e fomentar de forma universal o acesso aos serviços de saneamentos, pois perante os resultados do trabalho essas ações seriam essenciais para diminuir os indicadores de pobreza e extrema pobreza dos municípios do Estado do Rio Grande do Sul.

Cabe salientar as limitaçóes do trabalho. A principal limitação está associada a possível não exogeneidade das covariadas. A utilização de técnicas de econometria espacial dá-se no sentido de mitigar, ainda que parcialmente, os problemas de endogeneidade, sobretudo os causados pela dependência espacial presente nos dados utilizados. Se a fonte de endogeneidade for algum padrão espacial presente nos dados, os modelos econométricos 
espaciais são capazes de lidar com esse problema. Em alguns casos, entretanto, em que a fonte de endogeneidade é uma possível causalidade reversa entre a variável dependente e a (s) covariada(s), por exemplo, os modelos econométricos espaciais estimados no presente trabalho pouco podem fazer. A implicação direta da endogeneidade é não poder interpretar as estimativas como relaçóes causais, mas apenas correlaçôes.

\section{CONSIDERAÇÓES FINAIS}

A pobreza é uma situação que pode ser mensurada por diversas metodologias, desde as mais simples, que determinam a linha de pobreza pela renda (unidimensional), até as mais complexas, que consideram inúmeros fatores (multidimensional). O governo brasileiro utiliza medidas unidimensionais como, por exemplo, a linha de pobreza, adotada pelo Ministério do Desenvolvimento Social (MDS) na concessão do Bolsa Família.

O tema da pobreza tem ganhado cada vez mais repercussão desde os anos 1990, com a consolidação e ampliação de programas de transferência de renda, que beneficiam a população pobre, resultando em uma queda na porcentagem de famílias extremamente pobres e pobres no período pós Plano Real. Dessa forma, o estudo mais detalhado do tema é relevante para a avaliação dos programas de combate à pobreza. Ao estudar a situaçáo da pobreza nos municípios gaúchos, ainda que o estado possua uma incidência de pobreza e extrema pobreza baixa em comparação com outros estados brasileiros, busca-se analisar sua distribuição espacial no estado, bem como os fatores relacionados a ela.

Os resultados apontam que os municípios gaúchos estão aglomerados no que se refere a intensidade de pobreza, ou seja, municípios com baixa proporção de pobres tendem a estar cercados por municípios com a mesma característica e vice-versa Os resultados indicam ainda que a influência espacial ocorre nos municípios gaúchos e é significativa, constituindo, dessa forma, um elemento importante no estudo da pobreza no Estado.

Os resultados dos modelos estimados mostraram que a proporção de pobres e/ou extremamente pobres nos municípios do Rio Grande do Sul se associam significativamente do ponto de vista estatístico com o grau de formalização dos ocupados, índice de Gini, população total em domicílios particulares permanentes e proporção da população em domicílios com banheiro e água encanada.

Falando especificamente dos modelos econométricos espaciais, os resultados mostraram a existência de dependência espacial na relação entre a pobreza e as variáveis explicativas, uma vez que os testes de diagnóstico nos resíduos do MQO não permitem descartar a hipótese de que os mesmos estáo espacialmente correlacionados. Os dois modelos espaciais estimados apresentaram resultados relevantes para a proporçáo de extremamente pobres e pobres, resultando nos sinais esperados dos coeficientes a significância do modelo, por sua vez o modelo de Errro Espacial, apresentou a variável explicativa com maior coeficiente (mais intensa). 


\section{REFERENCIAL}

ALMEIDA, E. S. DE. Econometria Espacial Aplicada. $1^{\circ}$. ed. Campinas: Alínea Editora, 2012.

ANDRADE, E., LAURINI, M., MADALOZZO, R., \& PEREIRA, P. L. V. (2004).

Convergence clubs among Brazilian municipalities. Economics Letters, ${ }^{\circ} .83$ pp. 179 184.

ÁVILA, M. P. O Bolsa Família e a pobreza no Brasil: “detalhes” que fazem a diferença. 2013. 266 f. Tese (Instituto de Filosofia e Ciências Humanas) - Universidade Estadual de Campinas, Campinas, São Paulo. 2013.

ÁVILA, J.F. e BAGOLIN, I.P. (2014). Pobreza no Rio Grande do Sul: Uma análise exploratória da sua distribuição espacial a partir de indicadores Multi e Unidimensionais. Revista Estudo \& Debate, Lajeado, v. 21, n. 2, p. 25-47, 2014. ISSN 1983-036X.

ANSELIN, L. (1998). Spatial Econometrics: methods and models. Boston: Kluwer Academic.

RIO GRANDE DO SUL. SECRETARIA DA COORDENAÇÃO E PLANEJAMENTO (SCP). Atlas Socioeconômico do Estado do Rio Grande do Sul. Disponível em: http://www.atlassocioeconomico.rs.gov.br/conteudo.asp?cod_menu_ filho $=818 \&$ cod_menu $=817 \&$ tipo_menu $=E C O N O M I A \& c o d \_c o n t e u d o=1468$. Acessado em jan. de 2016.

CASTEL, R. As Metamorfoses da Questáo Social: uma crônica do salário. Vozes: Rio de Janeiro, 1998.

CAVALCANTI, D.M., COSTA, E.M. e SILVA, J.L.M. (2013). Programa Bolsa Família e o Nordeste: Impactos na renda e na educação, nos anos de 2004 e 2006. Revista Econ. Contemp., Rio de Janeiro, v. 17, n. 1, p. 99-128, jan-abr/2013.

CHIARINI, T. e YANO, N. (2010). Uma década de pobreza: Dinâmica da pobreza no Rio Grande do Sul, 1991-2000. $5^{\circ}$ Encontro de Economia Gaúcha. Disponível na internet: <http://www.fee.rs.gov.br/eventos/encontro-de-economia-gaucha/5-encontro-deeconomia-gaucha-2010/ > . Acessado dia: 15 de jan de 2016.

FLORAX, R. J. G. M.; FOLMER, H.; REY, S. J. Specification searches in spatial econometrics: the relevance of Hendry's methodology. Regional Science and Urban Economics, v. 33, n. 5, p. 557-579, set. 2003.

IBGE - Instituto Brasileiro de Geografia e Estatística. Censo Demográfico 2010.

Disponível na internet: <www.ibge.gov.br>, acessado dia 16/01/2016. 
LANGONI, C. (2005). Distribuiçáo de renda e desenvolvimento econômico no Brasil. $3^{\mathrm{a}}$ ed. Rio de Janeiro: FGV.

MILÁ, M.M. (2015). Income Concentration in a Context of Late Development: An Investigation of Top Incomes in Brazil using Tax Records, 1933-2013. Public Policy and Development Master Dissertation Paris School of Economics.

OSORIO, R. G.; SOUZA, P. H. G. F. Evoluçáo da pobreza extrema e da desigualdade de renda na Bahia: 1995 a 2009. Brasília: Ipea, 2012. (Texto para Discussão, n. 1.696).

ROCHA, S. Renda e Pobreza os impactos do Pano Real. Revista Brasileira Estudos Populacionais, 13 (2), 1998.

ROCHA, S. O programa Bolsa Família Evolução e efeitos sobre a pobreza. Economia e Sociedade. Campinas v. 20, n1 (41) p. 113-139. Abr 2011.

ROMERO, J. A. R. (2006). Análise especial da pobreza municipal do estado de Minas Gerais, 1991-2000. Anais do XIV Encontro Nacional de Estudos Populacionais, ABEP.

SEN, Amartya. Desenvolvimento como Liberdade. São Paulo: Companhia das Letras,2000.

SEN, Amartya. Desigualdade Reexaminada. Rio de Janeiro: Record, 2001.

SERRANO, R. M.; VALCARCE, E. V. Técnicas econométricas para el tratamiento de datos espaciales: la econometría espacial. [s.l.] Edicions Universitat Barcelona, 2000.

SILVA, L.D. C da, SOUZA, W.P. F. e SILVA. M.V.B (2013). Análise Espacial da Extrema Pobreza na Regiaao Nordeste: Uma Aplicaçáo para os Municípios. IX Encontro de Economia Baiana, set. 2013.

SOUZA. P.H.G.F e MEDEIROS. M. (2015). Top Income Shares and Inequality in Brazil, 1928-2012. Revista da Sociedade Brasileira de Sociologia ISSN 2447-2670. SID, Porto Alegre, v. 1, n. 1, p. 119-132, jul.-dez. 2015. 